\title{
Impact of well configuration on performance of steam-based gravity drainage processes in naturally fractured reservoirs
}

\author{
Hamed Akhondzadeh • Ali Fattahi
}

Received: 10 May 2013/Accepted: 5 May 2014/Published online: 8 June 2014

(C) The Author(s) 2014. This article is published with open access at Springerlink.com

\begin{abstract}
In spite of the immense resources of heavy oil and bitumen laid in naturally fractured reservoirs (NFR), the study of steam-assisted gravity drainage (SAGD) in this type of reservoirs is very limited and there is no study examining the impact of well configuration on the process performance. This numerical study investigates various steam-based gravity drainage process well patterns in NFR including conventional SAGD, off-set SAGD, staggered SAGD and vertical-injection SAGD. Furthermore, to obtain the best well location, sensitivity analysis of well spacing was carried out for each well pattern and the impacts of oil viscosity, preheating and fracture permeability and water saturation were assessed as well. The best well location case for staggered SAGD represented the ultimate oil recovery factor of $59 \%$ among all the cases with the SOR of 4.1 , while the best off-set SAGD case showed a low SOR of 3.7 with a moderate recovery factor of $57 \%$. With the exception of off-set well configuration, all well patterns illustrated their most efficient performance while having $8 \mathrm{~m}$ vertical well spacing. In cases of off-set and staggered patterns, horizontal well spacing is a crucial factor for oil production initiation. Original fracture water saturation is the key parameter to establish early communication between the wells and gives rise to fast steam
\end{abstract}

H. Akhondzadeh $(\square)$

Faculty of Petroleum and Renewable Energy Engineering, Universiti Teknologi Malaysia, No 63, Lane 13, Jahanara St., Shiraz, Iran

e-mail: ahamed3@live.utm.my

\section{A. Fattahi}

Faculty of Petroleum and Renewable Energy Engineering, Universiti Teknologi Malaysia, No 10, level 2, Sanei Bon bast, Fifth Ave, Fatemi St., Tehran, Iran

e-mail: faali3@live.utm.my chamber expansion as well. We found that preheating is a necessary part of the process in the off-set pattern due to horizontal well spacing. However, preheating operation does not play a significant role in processes with no horizontal well spacing even in high vertical well intervals and high oil viscosities, making SAGD process in NFR different from that in sandstones. We attributed these behaviors to zero irreducible water saturation in fracture which makes initial water saturation mobile. At the end, the term $\frac{S_{\mathrm{wf}} * K_{\mathrm{f}}}{\left(1+L_{\mathrm{hw}}\right) * \mu_{\mathrm{o}}}$ (where $S_{\mathrm{wf}}$ : fracture water saturation, $K_{\mathrm{f}}$ : fracture permeability, $L_{\mathrm{hw}}$ : Horizontal well spacing and $\mu_{\mathrm{o}}$ : oil viscosity) was introduced as the governing index of the oil production threshold.

Keywords Heavy oil - Steam-based gravity drainage . Naturally fractured reservoir - Enhanced heavy oil recovery $\cdot$ Well configuration

\section{Introduction}

Due to the current decline in conventional oil reserves, the commodity prices are increasing globally. As a result, oil industry has turned its attention to production techniques for known heavy oil deposits to solve this problem. Viscous oil trapped in carbonates (over 1.6 trillion bbl) is perceived as a huge potential resource for future energy supply which needs application of new technologies. While steam injection in sandstone reservoirs is known as a successful technology, there is a limited study on this process in fractured reservoirs.

There have been some thermal projects in fractured formations previously, all of which have been in pilot scale. Steam drive in Yates Field in Texas and Garland Field in Wyoming both in US, Cyclic steam stimulation in Cao-32

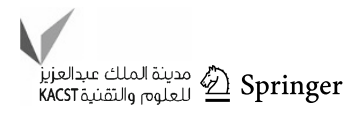


Field, China are some of the pilot scale experiences. Qarn Alam in Oman steam injection plant passed pilot test successfully and it was announced as a first full field scale steam injection in fractured media by shell as a partner company, Alvarado and Manrique (2010). Recently, Laricina Energy planned to apply SAGD pilot project at Saleski, Grosmont, Alberta, Canada, Cimolai et al. (2008).

\section{SAGD mechanism in sandstone}

The SAGD process involves two parallel long horizontal wells with one being located at the bottom as the producer and the other located at the top to inject steam continuously. Due to the density difference of oil and steam, steam tends to move upwards and sideways. Steam condenses at steam chamber interface and oil drains by gravity to the production well, Butler (1991). The field experience of SAGD process in UTF project in Alberta, Canada was successful (Edmunds et al. 1994 and Rouke et al. 1994) and there are many other SAGD processes being conducted in commercial stage in Alberta oil sands, Butler (2001).

Previous experiences and simulations have shown that well placement affects the recovery factor and breakthrough time. Some reservoir and operating parameters of three major oilsand projects in Alberta, Canada were studied by Shin and Polikar (2005) numerically, one of which was the injector to producer spacing. The results showed that an increase in the injector to producer spacing leads to an increment in the recovery factor, however, it prolongs the breakthrough time. For example, in $5 \mathrm{~m}$ well spacing, the recovery factor was $42 \%$ and increased to $49 \%$ for 15 meter well spacing.

Chen and Fong (1997) simulated a Saskatchewan type reservoir with different well pattern including conventional SAGD, 2-offset SAGD and 3-staggered SAGD. They suggested that an incremental amount of 10-15\% oil can be recovered by offsetting the producer from injector. An additional 5-10\% oil recovery over the off-set recovery is possible by staggering the well in SAGD process, however, at the expense of deteriorating SOR.

Vertical wells can also be used for steam injection above horizontal producers. There are several advantages in the use of vertical injection well. Firstly, this sort of well is cheaper and simpler to drill. Furthermore, exploration wells can be used as this kind of injectors since they have been drilled vertically at the beginning of the development plan. Also, it is possible to change the point of steam injection vertically as the project matures. Gao et al. (2002) studied various well patterns for a tar sand reservoir in china, numerically. The patterns included steam injection as cyclic steam stimulation and steam flooding in vertical wells as well as horizontal wells and finally the application of SAGD through vertical injection wells. They concluded that the latest one has the best oil recovery performance with oil recovery factor of $46.5 \%$ and an OSR of 0.27 . Their sensitivity analysis revealed that off-setting the vertical injection well and applying $20 \mathrm{~m}$ vertical well spacing between the injector and producer in this particular well configuration increases oil recovery performance.

Sawhney et al. (1995) carried out an extensive experimental, theoretical and scale up study of vertical injection SAGD. They concluded that horizontal injection SAGD is more efficient than vertical injection SAGD in the case of Cold Lake reservoir.

Numerical study of well configuration impact on oil recovery in gravity drainage processes for UTF project was carried out by Tamer and Gates (2009). Well configurations in that study included normal SAGD, vertical wells SAGD, vertical injection SAGD and their offsetting. In the term of oil recovery performance, off-set SAGD demonstrated the best results followed by normal SAGD with a negligible difference. Vertical wells SAGD was more efficient than vertical injection SAGD, economically.

\section{Thermal processes in fractured reservoirs}

Preliminary studies suggest that recovery efficiencies in fractured reservoirs may be increased by as much as $50 \%$ with the application of steam compared to that of low temperature processes. The key mechanisms enhancing oil production at high temperatures are the viscosity reduction, differential thermal expansion between oil and the pore volume and the appearance of some gases within matrix blocks. However, other mechanisms may also contribute to the increased oil production (Mollaei and Maini 2010). These mechanisms are relatively independent of oil gravity, making steam injection into fractured reservoirs equally attractive to light and heavy oil deposits (Reis 1992).

Britton et al. (1982) developed a new in situ steamflood method and assigned it the fractured assisted steamflood technology process (FAST), and tested the method in a South Texas tar sand deposit containing a viscous tar of 2 API. The first phase of the process consisted of horizontally fracturing from the injector toward the production wells and stimulating the fractures with high pressure steam. The horizontal fracture extended from the injection well to the producers, and steam was injected at high rates and pressures to hold the fracture open and to preheat the formation (fracture preheating phase). The results of the pilot showed that this process can be efficient and an average oil recovery of more than $50 \%$ was obtained.

After several steamdrive patterns evaluated in the fractured zones of the Lacq Superieur field, France, a high rate steam injection in a very low permeability zone through a $350 \mathrm{~m}$ horizontal well was performed. Sahuquet et al. 
(1990) simulated a horizontal injector and vertical producer process in this field because several tests showed that steam injection through a vertical well was not efficient due to the low permeability. The particularities of the Lacq Superieur operation is that the horizontal well is used as the injector to have a high steam injectivity in a low permeability carbonated facies and that the drain location is optimized to sweep a large area delimited by existing producing wells.

Experimental, numerical and pilot test of steam injection in Qarn Alam Field in Oman resulted in $27 \%$ oil recovery factor with an expected OSR of 0.3. Steam is injected in the crest of the reservoir and oil drains into horizontal producers. Oil recovery takes place in a process called thermally assisted gas oil gravity drainage (Shahin et al. 2006).

Although there are some studies investigating the effect of fracture on SAGD performance, almost in all of them the role of fracture could be considered just as a heterogeneity that acts as a path for conduction of fluids, Bagci (2004) and Fatemi (2009).

According to authors' literature review, there are just a few studies applying SAGD in fractured reservoirs. Sedaee and Rashidi (2006) simulated SAGD in an Iranian carbonate fractured reservoir. They mentioned that SAGD is the best thermal process, however, they did not present the results of the simulation. Das (2007) applied SAGD and CSS in fractured reservoir and compared them, numerically. Oil recovery was $34 \%$ with the SOR of 3 at the year 8. Furthermore, he carried out sensitivity analysis of some reservoir parameters including wettability and capillary pressure, fracture spacing, oil viscosity and well pattern. More steam was injected in the case of wider fracture spacing and it was attributed to the invasion and drainage from matrix and finally, he recommended more study. Matrix permeability did not have significant effect on the process performance. Water-wet rock illustrated $30 \%$ increased oil recovery factor compared to that of the oilwet case (without capillary pressure) in 8 years. He discerned that lower well spacings result in better performance for highly viscose oil and in the case of low viscose oil, staggered well pattern or higher well spacing has better performance. One of the abnormal features is constant steam injection rate of $1,200 \mathrm{bbl} /$ day subsequent to around 5 months, making it unusual in SAGD process since SAGD steam injection rate comes in bell-curved shape. Bagci et al. (2007) conducted a numerical study on SAGD involving steam alternating solvent (SAS) process in fractured reservoirs. They found that oil recovery performance of this process is higher than that of pure SAGD. This process was optimized at the injection schedule of 1-year steam and a half-year solvent injection, alternatively. Moreover, the examined fracture orientation did not lead to any differences in oil production performance.
However, the oil production performance was benefited by higher operating pressures and permeabilities.

Through numerical study, Murty et al. (2009) assessed various thermal processes to find the most efficient for shallow limestone fractured reservoir (rubble zone) in Bahrain. It was concluded that SAGD is not suitable due to low matrix permeability and low fracture porosity. Edmunds et al. (2009) analyzed core samples and past CSS pilots in Grosmont, Alberta and concluded the possibility of applying SAGD because of high bulk permeability, being in the order of higher than 10D. The reservoir rock texture includes centimeter-scaled karst and fractures, extensively. Moreover, single porosity model was proposed as approach to steam injection simulation since it was successful in history matching of CSS pilot. Yuan et al. (2010) created a 3D model for the Buffalo Creek Pilot Phase II of grosmont carbonate heterogeneous fractured reservoir and history matched the CSS pilot successfully. Then SAGD process performance was forecasted for layer $\mathrm{C}$ of this field. Their simulation showed that the lateral expansion of steam chamber with excellent performance reached its peak production rate of $264 \mathrm{~m}^{3} /$ day at 3 years and subsequently stabilized at around $87 \mathrm{~m}^{3} /$ day. A dual permeability/dual porosity approach was used in this study. Cimolai et al. (2010) gave solution for Grosmont type layered carbonate. SAGD simulation was started in layer D underling by layer C. Subsequently, a producer in the later layer at bottom, separated by marlstone, started to produce while this zone had been heated by conduction of overburden, layer D, by expanded steam chamber.

Solanki et al. (2010) discussed the first solvent added SAGD process called solvent cyclic-SAGD that has been planned to apply in Grosmont, Alberta. Subsequent to preheating phase, steam chamber creation and reaching overburden, a heavy solvent will be co-injected followed by the co-injection of a lighter hydrocarbon such as propane. When the steam chamber starts the blow down phase, a non-condensable gas such as methane will be injected to maintain the steam chamber pressure.

Laricina Company (Laricina Company Operation Report 2010) started to apply SAGD (1,800 b/day capacity) at Saleski, December 2010 as the world's first SAGD carbonate project and oil production was initiated in the spring of 2011. The commercial phase will be initiated in late 2013 with $12,500 \mathrm{~b} /$ day capacity.

Fractured reservoirs are made up of two systems; matrix and fracture. The flow toward the wellbore is considered to take place in the fracture network, while the matrix continuously feeds the system of fracture. Moreover, in some conditions vugs are included in the reservoir formation rock. These differences change the oil recovery mechanism and steam injection process rather than sandstone. Accordingly, although thermal recovery in sandstone is a 
Fig. 1 Well patterns from left to right: conventional SAGD, offset SAGD, staggered SAGD and vertical-injection SAGD
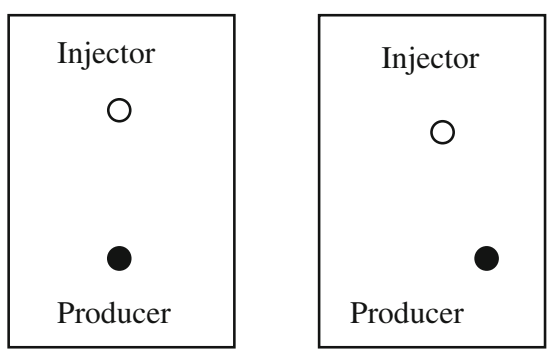

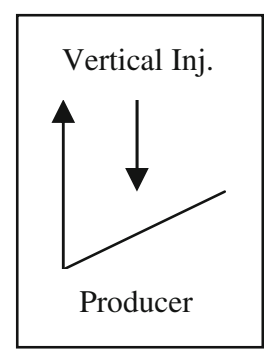

mature process, it is in very early stages of application in fractured reservoirs and need extensive study. Studies which focused on SAGD in fractured reservoirs are quite rare and there is only few published numerical study. Furthermore, there is not any study investigating the impact of well configuration on SAGD in fractured reservoirs. In this paper, the impact of various well configurations on steam-based gravity drainage process is studied. The cases of investigation are conventional SAGD, off-set SAGD, staggered SAGD and vertical injection SAGD, which are presented in Fig. 1 and the sensitivity analysis of well spacing was carried out for each pattern. It should be mentioned that four different vertical well spacing were defined for each well pattern and these vertical intervals were the same in all well patterns. In addition, higher oil viscosity case was simulated and the conditions the preheating needed were analyzed. Higher fracture water saturation and permeability were also examined to assess the expected beneficial effects of these parameters.

\section{Simulation model}

The CMG STARS was used to simulate the mentioned processes. The model dimensions in all processes were the

Table 1 Reservoir and fluid properties of simulation model

\begin{tabular}{ll}
\hline Reservoir pressure $(\mathrm{kPa})$ & 2,500 \\
Reservoir thickness $(\mathrm{m})$ & 30 \\
Matrix permeability $(\mathrm{mD})$ & 50 \\
Fracture permeability $(\mathrm{mD})$ & 2,500 \\
Matrix porosity & 0.25 \\
Fracture porosity & 0.02 \\
Matrix oil saturation & 0.75 \\
Fracture oil saturation & 0.7 \\
Oil viscosity at $75 \mathrm{~F}(\mathrm{cp})$ & 40,000 \\
Rock compressibility & $9.6 \times 10^{-6} / \mathrm{kpa}$ \\
Formation heat capacity & $2,350 \mathrm{kj} / \mathrm{m}^{3} \mathrm{k}$ \\
Rock thermal conductivity & $6.6 \times 10^{5} \mathrm{~J} / \mathrm{m}$ day C \\
Water thermal conductivity & $1.15 \times 10^{4} \mathrm{~J} / \mathrm{m}$ day C \\
Oil thermal conductivity & $5.35 \times 10^{4} \mathrm{~J} / \mathrm{m}$ day C \\
Gas thermal conductivity & $1.4 \times 10^{2} \mathrm{~J} / \mathrm{m}$ day C \\
\hline
\end{tabular}

same with $106 \times 90 \times 33 \mathrm{~m}^{3}$. The length of horizontal wells was considered $90 \mathrm{~m}$ to reduce the simulation run time. In the case of vertical injection SAGD, the grid system was $55 \times 15 \times 14$ and for the other processes was $55 \times 1 \times 14$. The reservoir and fluid properties brought in Table 1 approximately represent the typical characteristics of fractured reservoir. Dual porosity with vertical subdivision option was used to capture gravity drainage precisely. Matrix block size of $1 \mathrm{~m}$ was used for all models with 5 divisions vertically. Oil-wet with gas/oil capillary pressure was defined as the reservoir rock and Cold Lake type dead oil was assumed. All processes were under the operating pressure of $2,550 \mathrm{kPa}$. No preheating was applied at the start of processes.

\section{Results and discussion}

Oil recovery mechanism

Before study of process performance, heating and oil recovery of all processes are discussed to some extent. The following mechanisms mentioned here is the result of study presented in a previous author's paper (Fattahi et al. 2012) which is thoroughly discussed in that paper. In oil-wet FR, steam enters fractures and then heats the matrix block, however, oil cannot move out from matrix until fractures are filled with steam, therefore oil drains from the matrix to fracture due to density difference between oil in matrix and steam in the fracture. The extracted oil from matrix to fracture is drained to producer via fracture by gravity. However, at the bottom part of steam chamber, fracture oil saturation is high, and consequently it prevents expulsion of oil from matrix, although it is inside the steam chamber. Gas/oil capillary pressure prevents oil extraction from matrix before the oil saturation reaches its residual amount.

In this process, a large amount of water was produced at the start of process while oil production is not occurred yet. Produced water reached its peak in few months of operation, while oil production peak occurred at 5 years. Similarly, a large amount of steam is injected corresponding to produced water. Due to the presence of mobile water in fracture, water is produced from the start of process largely 
and makes empty space for large steam injection, while in sand stone, the heated oil should be produced to make empty space for steam injection, making the process slow and providing enough time to sideways expansion. This issue also creates larger steam chamber in FR compared to sandstone at early time.

\section{Conventional SAGD pattern}

To investigate the impact of well spacing, four different intervals of $2,7,12$ and $17 \mathrm{~m}$ were considered for conventional SAGD pattern. Figure 2 illustrates the cumulative oil production and cumulative steam oil ratio (CSOR) in the four cases of conventional SAGD. Each curve's name for both parameters is ended with the distinct well spacing of that case in meter.

As it is seen in the figure, the ultimate cumulative oil production has been almost the same at $38 \mathrm{Mm}^{3}$ with negligible variations for all cases and given the original oil of $66 \mathrm{Mm}^{3}$, all cases resulted in a recovery factor of $57 \%$. It should be noted that although the cumulative produced oil at the end of the period is almost the same for all cases, the early oil rate versus well spacing shows a bell-shaped curve, hitting its peak at $7 \mathrm{~m}$ case. This happens as the result of the communication establishment interval which lasts longer for higher well spacings, hence postponing desirable oil production rates to near 4 months after the initiation of the operation for the $17 \mathrm{~m}$ case. On the other hand, a high well spacing results in higher amounts of oil being swept toward the production well initially. The $7 \mathrm{~m}$ case early oil production superiority than others therefore, is owing to the fact that applying this spacing for the wells would locate them far but yet near enough to make a communication shortly. Accordingly, being benefited from both aspects, a large amount of oil is swept within a short course of time in the $7 \mathrm{~m}$ case.

Unlike the cumulative produced oil, cumulative SOR differs somewhat for the conventional SAGD cases. After a high peak in all the CSOR curves at very early time showing the duration of the wells communication establishment, all falls sharply to their nadir owing to the early expansion of the steam chamber in the reservoir sweeping large amount of oil. There are two salient factors governing the shape of the dip in the SOR curve. On the one hand, the higher the well spacing, the bigger the steam chamber and in turn, resulting in lower SOR quantities, placing the case $12 \mathrm{~m}$ at the lowest SOR value among the three first cases. On the other hand, too far distant wells would result in early heat loss through overburden, hence increasing the value of the dip point in SOR curve and giving the case $17 \mathrm{~m}$ a higher SOR at its turning point than the 7 and $12 \mathrm{~m}$ cases. Subsequently, all curves are followed by upward trends toward the end of the operation. In spite of the higher early-time CSOR observed in this case, the $2 \mathrm{~m}$ instance resulted in the lowest ultimate CSOR of 3.8 and higher well spacings revealed slightly less favorable results of this value. However, no large distance was seen between the lowest and highest amounts of ultimate cumulative oil recovery and CSOR, the $7 \mathrm{~m}$ case yet takes the first place of performance among the 4 cases according to the two evaluated parameters along with the early oil recovery rate profile.

To be noted in assessing the results is that such moderately viscous oil, although not in high rates, has moved toward the production well without applying pre-heat in the SAGD process with almost the same operating pressure in wells, while in sandstone reservoir a preheat period is often necessary to initiate the process. This result was attributed
Fig. 2 Cumulative oil production and cumulative SOR for conventional SAGD cases with different well spacing

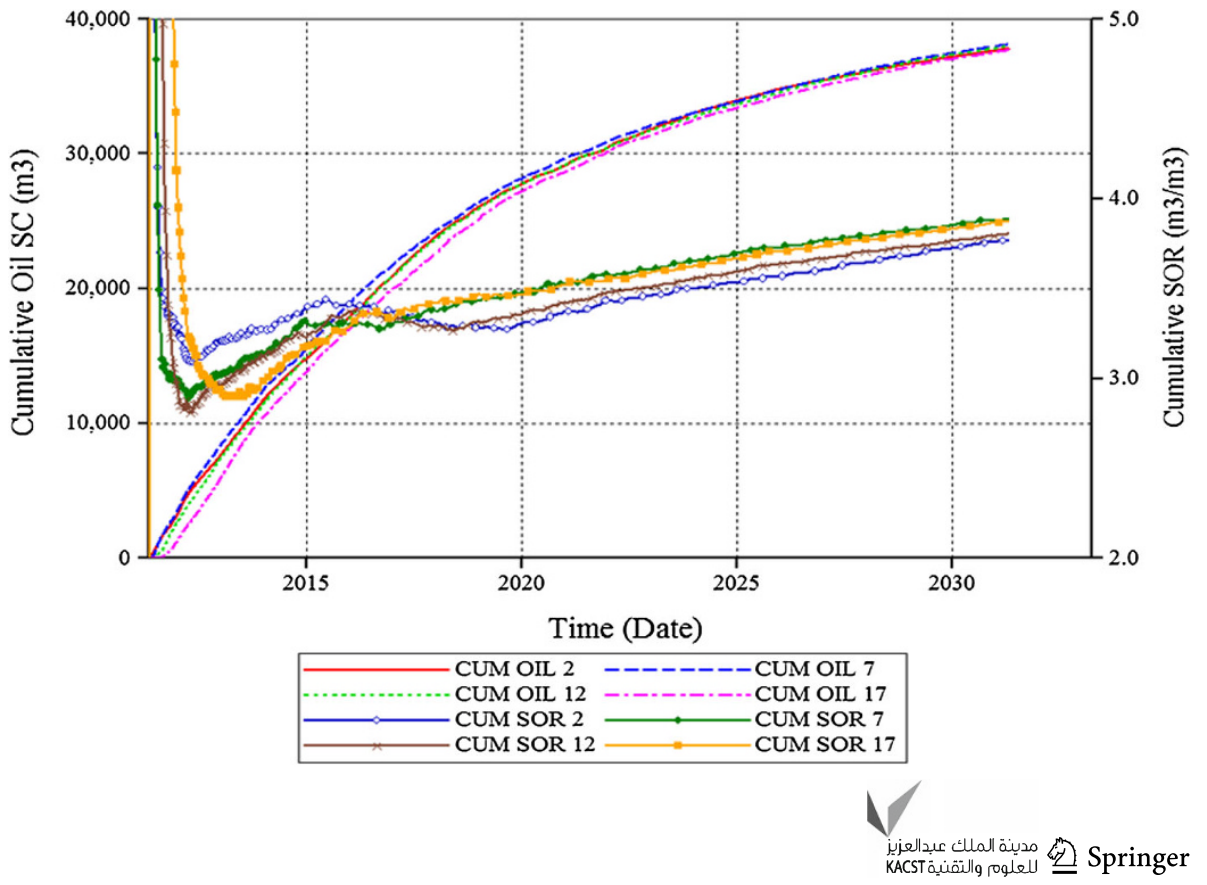


to the cross-like fracture relative permeability curve of this sort of reservoir. Accordingly, a sensitivity analyses was performed to investigate the mentioned claim.

Figure 3 demonstrates the performance of two conventional SAGD cases having the same operating and reservoir conditions. Considering the "conventional SAGD $7 \mathrm{~m}$ " as the base case, a new case was defined in which the relative permeability curve for fracture network was the same as that of matrix and was captioned "conventional SAGD 7, same $\mathrm{Kr}$ " in the figure. Similar to the well spacing study, the main performance comparison elements are cumulative oil production and SOR in this sensitivity analysis. The adverse effect of having non-zero endpoints in the saturation axis of relative permeability curve than the crossshaped one for fracture was much severe that makes it difficult to draw an analogy between the poor performance of this case and the "conventional SAGD $7 \mathrm{~m}$ " case. Whereas the "conventional SAGD $7 \mathrm{~m}$ " case has started to produce oil almost from the beginning of the process, a 20-month delay is seen in the cumulative oil production curve of the "conventional SAGD 7, same Kr" case. This case then started to produce oil with unfavorable rates toward the end of the period terminating with just $14 \mathrm{Mm}^{3}$ cumulative oil which corresponds to as low as $21 \%$ recovery factor. Likewise, very undesirable results for CSOR were observed in this instance. While the CSOR was less than 3.9 during the operation and ended with this quantity in the "conventional SAGD $7 \mathrm{~m}$ " case, the other case never fell beyond 4 throughout the operation time and ended with 6.2.

Accordingly, as it was expected, cross-shaped fracture relative permeability curve in fractured reservoirs was concluded to result in the free movement of the initial water inside the fracture and this is the principal reason for the early initiation of the oil production in such media. Furthermore, this feature has a significant effect on the steam chamber expansion throughout the operation period as well.

\section{Off-set SAGD pattern}

Figure 4 depicts the cumulative oil production and CSOR for four different cases of off-set pattern with all having equal vertical well spacings with those in the conventional SAGD study. Horizontal spacings were considered the same as the vertical interval for each distinct case. Similar to conventional SAGD cases, each parameter's label is ended with the specific distance between the production and the injection wells for that particular case.

As illustrated in Fig. 4, all cases except "off-set SAGD $3 \mathrm{~m}$ " case have initiated to produce oil after a remarkable delay. While there was no noticeable difference between the cumulative oil production and CSOR values for conventional SAGD cases, there are substantial alterations seen in these two factors for off-set pattern instances. The case having $3 \mathrm{~m}$ spacing between the wells started to produce oil from very early time and ended with $38 \mathrm{Mm}^{3}$ cumulative produced oil and the CSOR of 3.7. This instance was closely followed by the second small spacing case of $9 \mathrm{~m}$ which ended with the same CSOR and slightly lower cumulative oil production. The latter case, however, delayed to produce for over a year after the beginning of the process.

The two other cases revealed less favorable results particularly in cumulative oil production. While "off-set SAGD $16 \mathrm{~m}$ " case began to produce oil after 3 years of operation, this instance ended with somewhat lower cumulative oil production than the two previous off-set
Fig. 3 Cumulative oil production and cumulative SOR for relative permeability sensitivity analysis

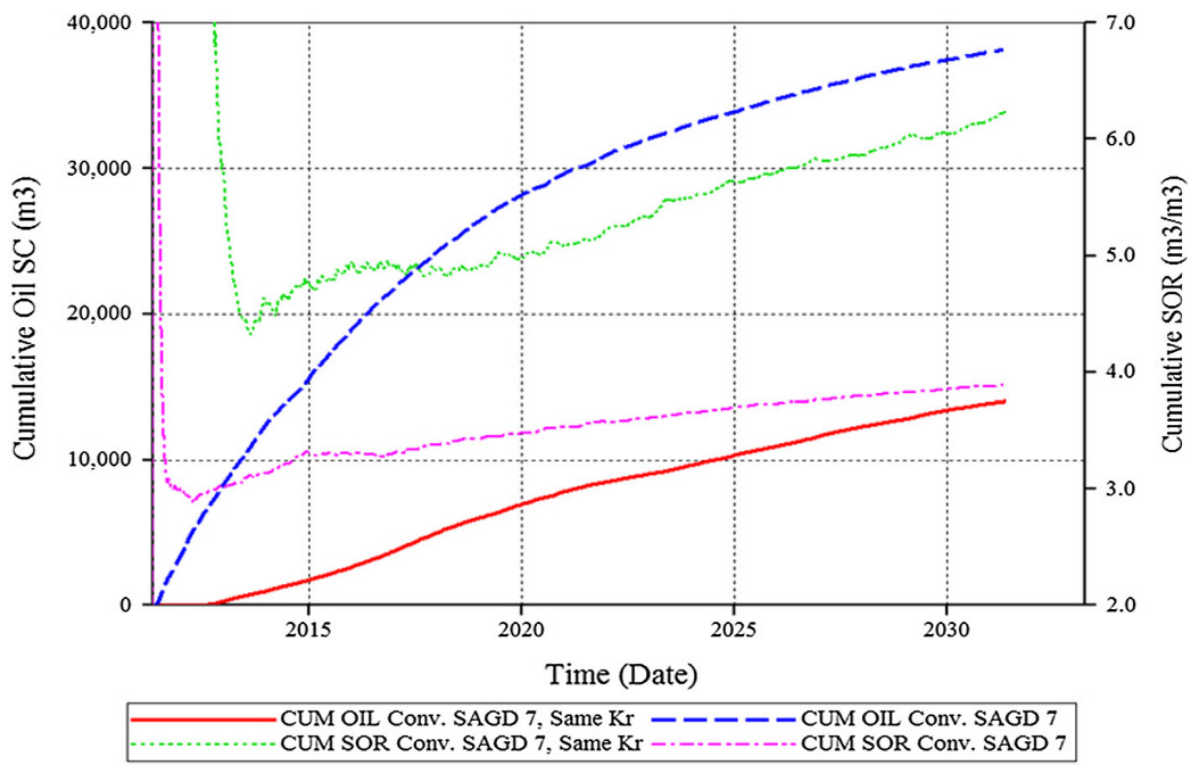


Fig. 4 Cumulative oil production and cumulative SOR for off-set SAGD cases with different well spacing

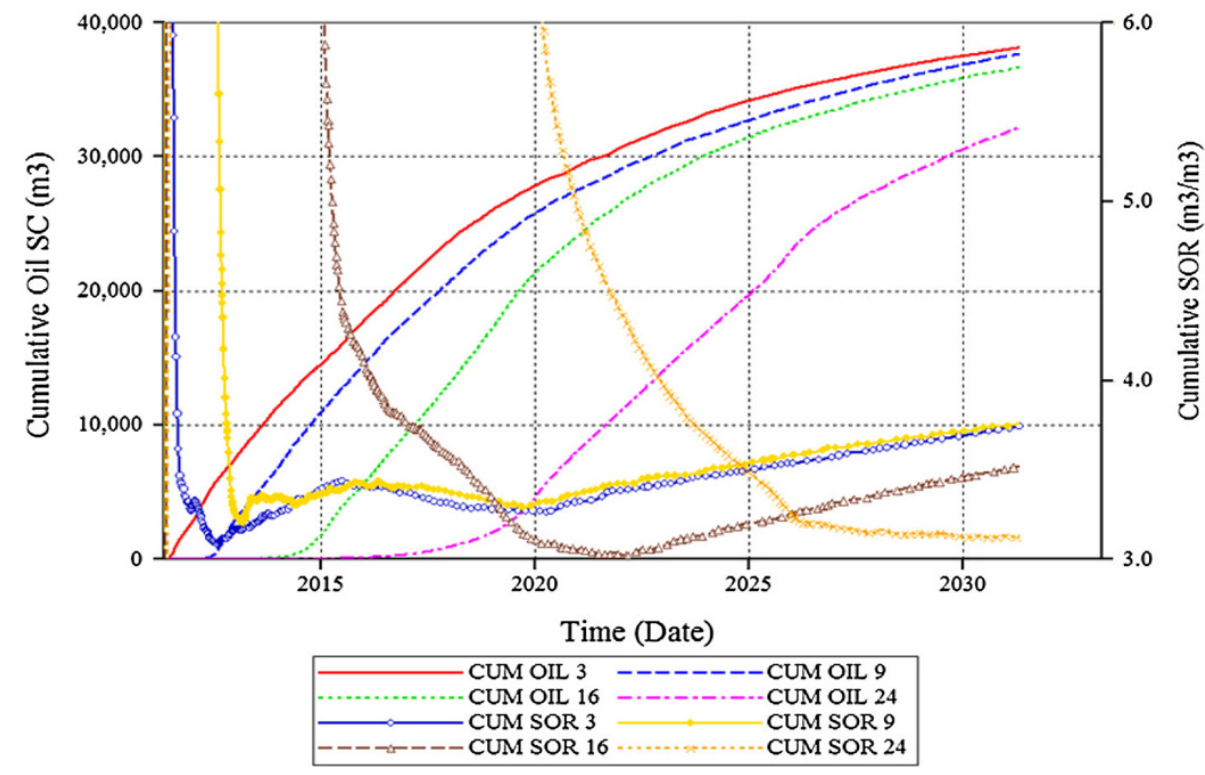

cases with $36.7 \mathrm{Mm}^{3}$. The last off-set case having $24 \mathrm{~m}$ distance between the wells demonstrated the worst results. The oil production curve remained at negligible amounts for less than 6 years for this case and the ultimate oil production was far less than the three previous instances with $32 \mathrm{Mm}^{3}$. The CSOR at the end of the defined period was 3.5 and 3.1 for the two last cases, respectively. As is obviously seen in the Fig. 4, the cumulative oil production curve in the three first off-set cases has approached maturity in the given period, however, in the last case this curve has a long way to reach that level and that is the reason of CSOR curve getting terminated with downward trend, on the contrary to the three other cases. The recovery factor of the first off-set example, having $3 \mathrm{~m}$ distance between the wells, was the same as that of conventional SAGD cases being $57 \%$. The three other off-set cases resulted in recovery factors of 56,55 and $48 \%$, respectively.

The delay in the oil production in off-set SAGD cases lasts significantly longer than that of conventional SAGD. This long-lasting delay is the result of the horizontal spacing of the wells. The more the horizontal spacing between the wells, the more the inclination from the vertical orientation between them (if the vertical spacing is constant) and in turn, the later the communication between the wells is established. It is obvious that the vertical spacing between the wells also has a direct relationship with the communication establishment period. However, the later parameter's effect is much less intense compared to that of horizontal distance.

\section{Staggered SAGD pattern}

The cumulative oil production profile for the four defined staggered cases is brought in Fig. 5. The vertical spacing in these cases is exactly the same as the previous well patterns, while the horizontal spacings differ from those in offset configuration. Similar to previous sections, the injectorto-producer well spacings are brought in meter at the end of each case's title. The oil production quantities in each curve represent the summation of cumulative produced oil through both producers.

One of the most conspicuous features in the cumulative oil production figure of different staggered SAGD cases is the early time separation of $8 \mathrm{~m}$ case curve from the others which reveals higher early oil rates in this case. Furthermore, this well configuration in SAGD process has led to sweeping the most oil at the end of the operation among the four staggered cases as well as among all the previously discussed cases with $39.3 \mathrm{Mm}^{3}$, equivalent to a recovery factor of $59 \%$. A corresponding behavior is seen in the figure of CSOR, Fig. 6, for this case. The most efficient early time CSOR among the staggered cases was observed in this example, however, this case took a middle place regarding the CSOR at the terminal time. Of importance in this case is taking the highest place of cumulative oil production throughout the process among all the cases making it the most favorable staggered well spacing.

The least efficient staggered SAGD performance was witnessed while applying $2 \mathrm{~m}$ distance between the injection well and each of the producers in staggered well configuration pattern. Whereas this case started to produce oil from almost the beginning of the operation, it ended with $38.2 \mathrm{Mm}^{3}$ cumulative produced oil being the least among all the staggered cases. To render this case as the least efficient one in this particular well pattern, the CSOR is considerably higher than the others almost throughout the operation period ending at 4.3.

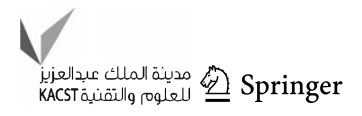


Fig. 5 Cumulative oil production for staggered SAGD cases with different well spacing

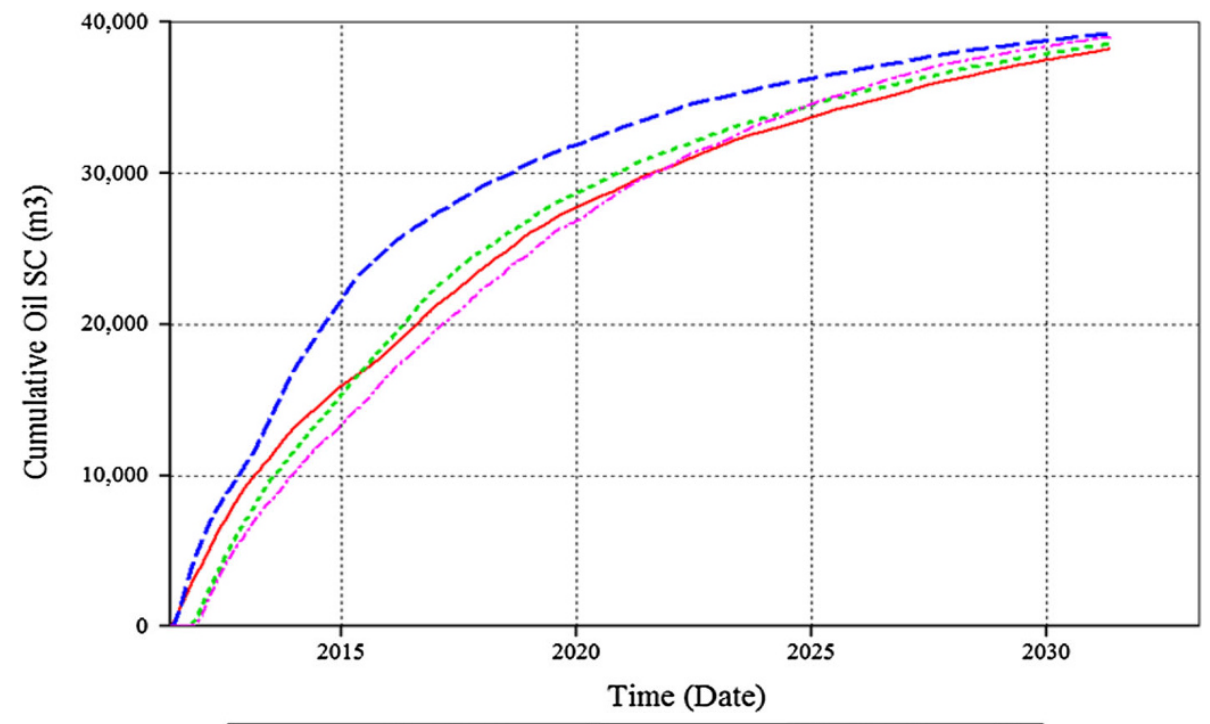

CUM OIL Staggered $2-----$ CUM OIL Staggered 8 CUM OIL Staggered 13 -.-.-.-.-. CUM OIL Staggered 18

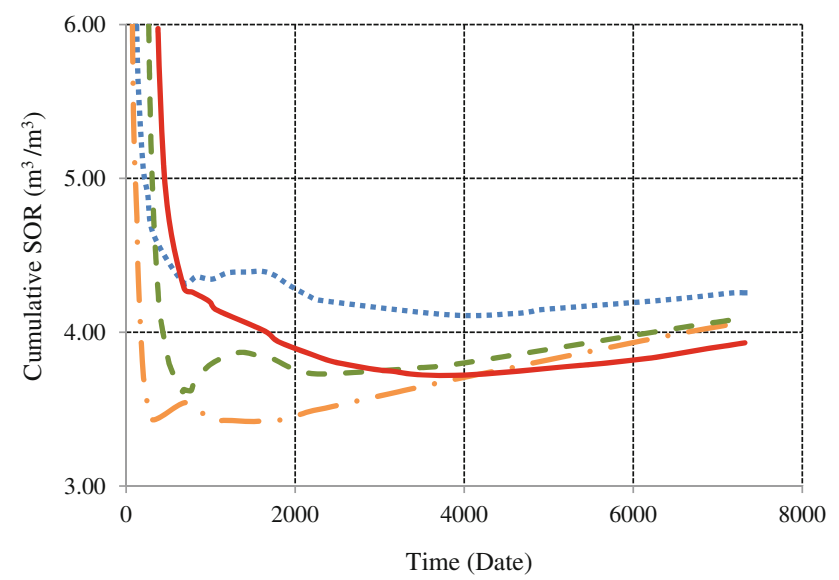

$$
\begin{gathered}
=\ldots=\text { CUM SOR Staggered } 2 \\
-\quad-\text { CUM SOR Staggered } 13 \quad \text { CUM SOR Staggered } 8 \\
\text { CUM SOR Staggered } 18
\end{gathered}
$$

Fig. 6 Cumulative SOR for staggered SAGD cases with different well spacing

The case applying $18 \mathrm{~m}$ distance between the injection and the production wells in staggered pattern revealed one of the most desirable results. While the ultimate cumulative oil of this case follows the highest of this value in staggered pattern seen in the $8 \mathrm{~m}$ case, the final CSOR for this case has been lower with 3.9, making this well configuration one of the most promising case among the studied staggered SAGD instances. A delay in oil production at the beginning of the process in this case should be noticed. The $13 \mathrm{~m}$ case has illustrated middle results both in its cumulative oil production and CSOR.
Vertical-injection SAGD pattern

As the last well configuration, the effect of vertical well spacing in vertical-injection SAGD was studied in three distances of 5,10 and $15 \mathrm{~m}$ and then compared to the other patterns. Results of the simulation are presented in Fig. 7 in the terms of cumulative oil recovery and CSOR. In the early time of process within 5 years, $15 \mathrm{~m}$ well spacing case showed the highest oil recovery among all the three well spacings, however, this well interval case revealed less favorable oil production later, reaching the lowest ultimate oil recovery factor of $48 \%$. The case of $10 \mathrm{~m}$ well spacing extracted the most oil at the end of the process, resulting in a terminating oil recovery factor of $50 \%$. This case also represented the best final SOR of 3.5. As a simple rule, it can be stated that a medium well spacing in verticalinjection SAGD leads to the best performance.

Viscosity sensitivity analysis

A viscosity sensitivity analysis was carried out on the offset and conventional well patterns to observe the impact of higher viscosities on the process. In the off-set well pattern, the second case was chosen for this sensitivity analysis. The reason for choosing "off-set SAGD $9 \mathrm{~m}$ " case was that the adverse effect of higher viscosity of heavy oil was to be investigated, therefore, the first case, having just $3 \mathrm{~m}$ spacing between the wells was perceived to be an incompetent instance to highlight that negative effect. On the other hand, the injection and production wells in the next two cases of off-set pattern study were conjectured to be located too far to be able to sweep such heavy oil having a 
Fig. 7 Cumulative oil production and cumulative SOR for vertical-injection SAGD cases with different well spacing

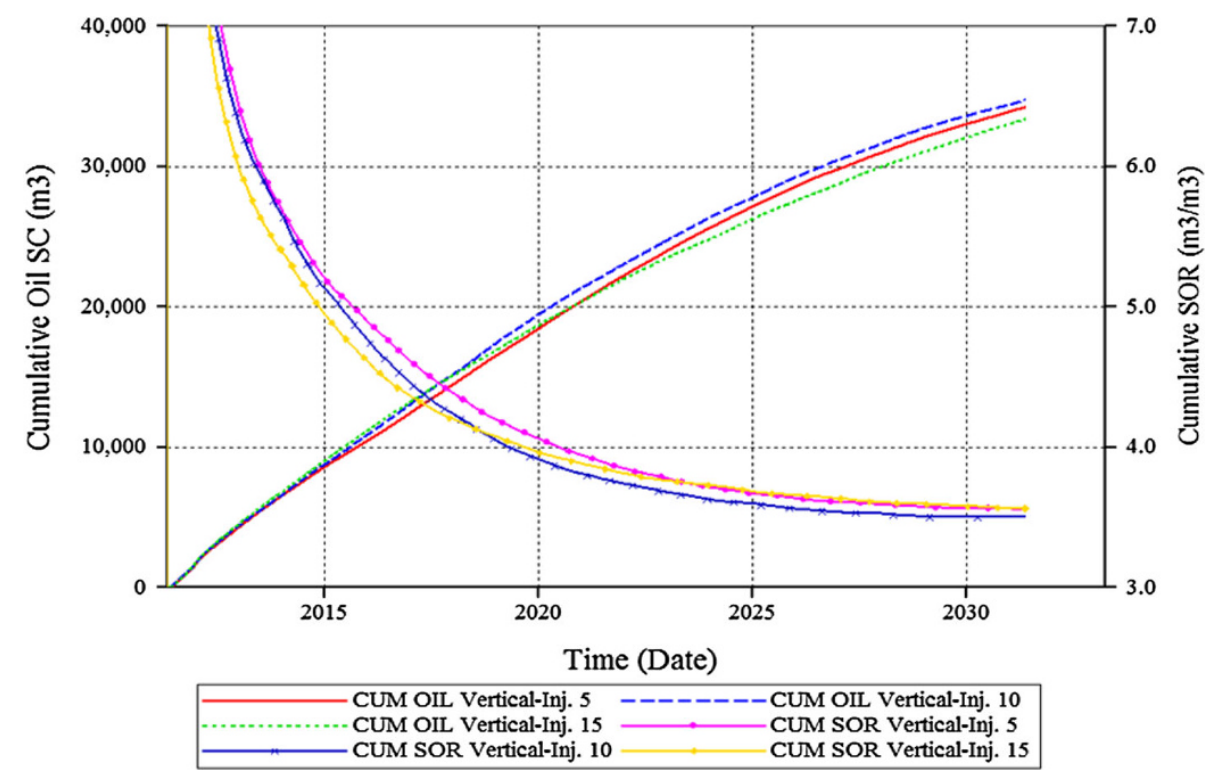

viscosity in order of $300,000 \mathrm{cp}$ at the original reservoir temperature.

Accordingly, five cases were defined for the viscosity analysis study including "off-set SAGD 9 m" example and a higher-viscosity alternative of this case as the base case for low and high viscosity to compare the results and evaluate the negative effects. The third case of investigation in this sensitivity analysis was the higher viscosity base case with a preheat period of 90 days in both wells to observe how this operation benefits the process.

Previously, it was suggested that the production of heavy oil in such fractured reservoirs is feasible owing to the relative permeability curve and relatively higher saturation of water in fracture in this kind of reservoir. While the former was discussed before, the effects of the water saturation in the fracture section of fractured reservoirs will be discussed in this sensitivity analysis by defining a new alternative from the base case of higher viscosity, having $50 \%$ water percentage in fracture section as initial water saturation rather than the $30 \%$ water saturation in all other cases. The last case of this sensitivity analysis was a higher fracture permeability as an alternative of the high viscosity base case to examine the expected positive effect of a higher permeability.

Figures 8 and 9 illustrate the cumulative oil and cumulative steam oil ratio for the four mentioned cases defined for viscosity sensitivity analysis, respectively. As can be seen in Fig. 8, while the delay before producing oil has been about a year for the "off-set SAGD $9 \mathrm{~m}$ " case, the base case of higher viscosity possessing almost tenfold viscosity has not been able to produce the heavy oil for over 3 years. It should be noted that the entire reservoir parameters including the water saturation and the relative permeability curve of the reservoir have not been changed, therefore, the unfavorable result of the production postponement for more 2 years over "off-set SAGD 9 m" case is attributed only to the high viscosity of oil. Whereas final cumulative oil production has been $37.6 \mathrm{Mm}^{3}$ for the former case leading in a recovery factor of $56 \%$, the base case of higher viscosity has revealed substantially less promising result of $25.5 \mathrm{Mm}^{3}$ ultimate oil production, corresponding to a recovery factor of $38 \%$.

As an approach to enhance the performance of the offset SAGD process, a 90-day preheating period was introduced to the higher viscosity case. Desirably, the communication establishment between the wells lasted for half a year to achieve in this case, far sooner than the high viscosity base case and even noticeably faster than "off-set SAGD $9 \mathrm{~m}$ " case. The preheated case, however, resulted in a terminal cumulative oil production of $31 \mathrm{Mm}^{3}$ equivalent to $47 \%$ recovery factor, being significantly higher than "off-set $9 \mathrm{~m}$, High Visc" case, emphasizing the importance of preheating in early oil production as well as higher ultimate oil recovery factor. It should be noted that ultimate oil recovery factor of "off-set $9 \mathrm{~m}$, High Visc-Preheat" is yet considerably lower than that of "off-set SAGD 9 m" case highlighting the negative effect of higher oil viscosities in oil recovery performance in steam based gravity drainage processes.

As the next case of investigation in this sensitivity analysis, the effect of higher water saturation was examined by defining an alternative of the high viscosity base case with just varied water saturation in the fracture equal to $50 \%$ from the $30 \%$ in the base case. As expected, much better results of cumulative oil production and CSOR were obtained in this case in comparison with the high viscosity 
Fig. 8 Cumulative oil production for viscosity sensitivity analysis

Fig. 9 Cumulative SOR for viscosity sensitivity analysis
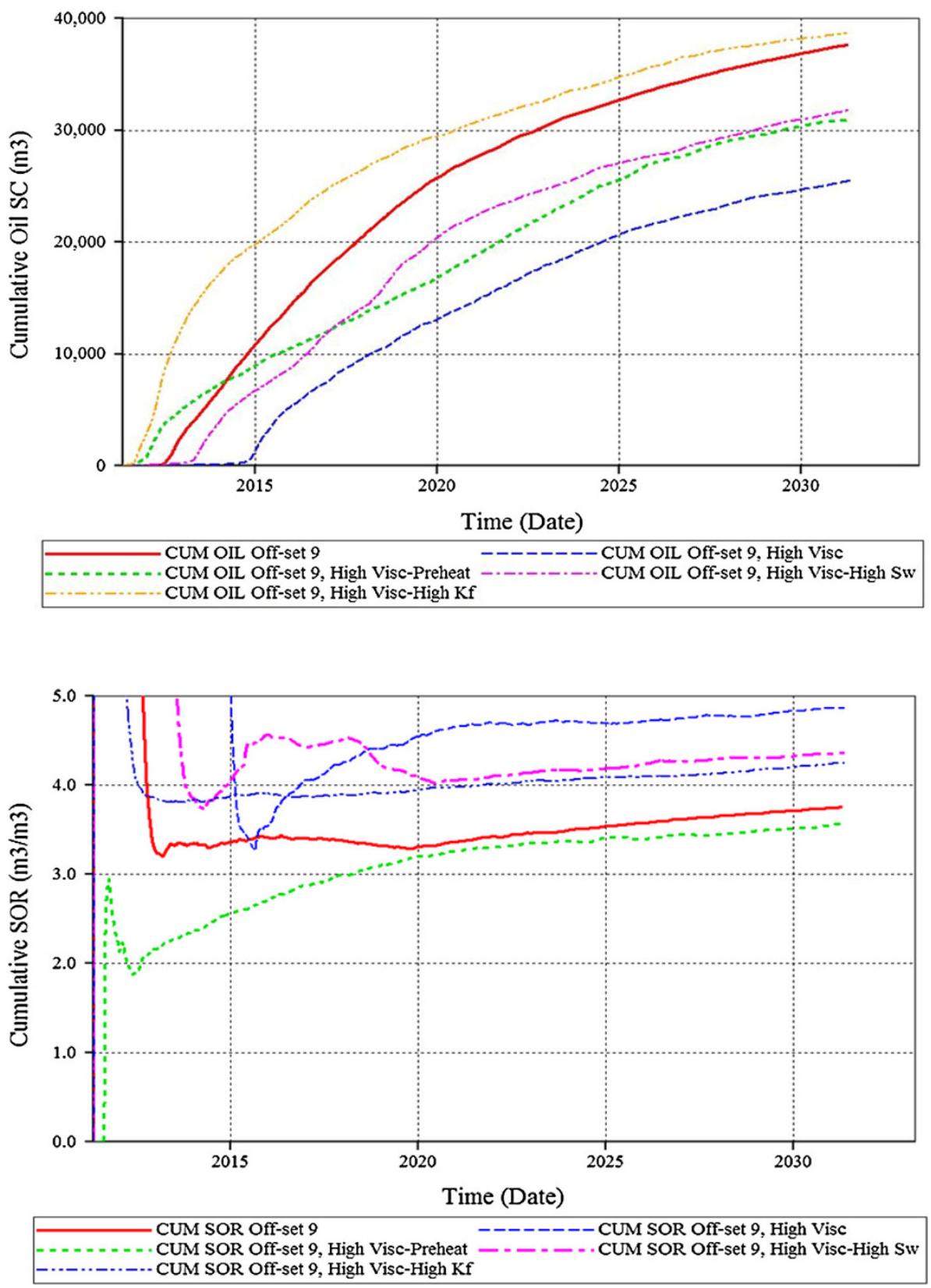

base case. Although this instance commenced to produce oil significantly later than the preheated case, the delay was considerably shorter than the high viscosity base case, "off-set $9 \mathrm{~m}$, High Visc". It is notable that the terminal cumulative oil production of this case has been $6.3 \mathrm{Mm}^{3}$ higher than that of "off-set $9 \mathrm{~m}$, High Visc" case and in opposite to the result of communication establishment period, the cumulative oil production in this case has slightly surpassed the preheated case and ended with almost 1 percent more recovery factor over that case with $48 \%$.

To investigate the impact of fracture permeability on process initiation, the fracture permeability of "Off-set 9 ,
High-Visc" which has been the high viscosity base case was increased fourfold to 10D. Figure 8 illustrates the great advantageous impact of the higher fracture permeability on the threshold of oil production. While in the case of "Offset 9, High-Visc" oil production started after 4 years, this delay decreased to only 3 months in the case of higher fracture permeability. Moreover, final oil recovery reached $58 \%$ at the end of 20 years compared to $38 \%$ for the lower fracture permeability case.

The cumulative steam oil ratio of the five discussed cases of viscosity sensitivity analysis is seen in Fig. 9. The worst result of CSOR is seen in the curve of "off-set $9 \mathrm{~m}$, High Visc". As it is obviously noticed, CSOR in this case 
has fallen below 5 after almost 4 years of operation by around 2015, and in accordance with the cumulative oil production curve, suggesting that no significant oil production has obtained prior to that time. Moreover, this curve has resulted in the least favorable ultimate CSOR of 4.9 , while this value for "off-set SAGD $9 \mathrm{~m}$ " case has been 3.8 indicating the negative effect of higher oil viscosity. The higher initial water saturation case illustrated more desirable results than the high viscosity case but yet not enough promising by resulting in an ultimate CSOR of 4.4. The preheated case demonstrated the most conspicuous behavior compared to other cases. This case never exceeded the CSOR of 4 throughout its operation period. The very promising behavior of this case was certainly attributed to the beneficial effects of the preheating period. The preheated case ending at CSOR 3.6, revealed the most desirable result for this value over all the other cases of this sensitivity analysis including "off-set SAGD $9 \mathrm{~m}$ " case. For the higher fracture permeability, the ultimate SOR reduced effectively to 4.2 from 4.9 in the base case of high viscosity.

A viscosity analysis on conventional SAGD pattern was examined for various well spacings of higher viscosity to compare the results with the previously discussed low viscosity cases of this configuration. The results' trend based on different well spacings was the same with the low viscosity conventional SAGD. However, it is notable that even in the worst case of conventional SAGD high viscosity, the delay in the oil production initiation was just in order of months while it was in order of years in the higher spacing cases of Offset pattern. The results of conventional SAGD high viscosity were not brought since no significant alteration was seen between these cases and the conventional SAGD low viscosity cases.

\section{Discussion}

All of the simulations results of CSOR, cumulative oil production and ultimate recovery factor are brought in Table 2 and the best case of each well pattern were compared. Staggered SAGD resulted in the highest oil recovery factor of $59 \%$ among all of the patterns; however, it leads to an undesirable SOR of 4.1. It should be noticed that in this pattern three wells are involved for each distinct zone rather than the two in the other well configurations, hence suffering the economy of the process. The Off-set case performance is better than conventional SAGD in the both terms of recovery factor and SOR being $57 \%$ and 3.7, respectively. Having SOR of 3.5, Vertical-Injection SAGD showed the best thermal
Table 2 Cumulative SOR, cumulative oil production and recovery factor for all the simulation cases

\begin{tabular}{llll}
\hline & SOR & $\begin{array}{l}\text { Cumulative oil, } \\
1,000 \mathrm{~m}^{3}\left(\mathrm{Mm}^{3}\right)\end{array}$ & $\begin{array}{l}\text { Recovery } \\
\text { factor }(\%)\end{array}$ \\
\hline Conventional SAGD 2 & 3.8 & 37.8 & 57 \\
Conventional SAGD 7 & 3.9 & 38.1 & 57 \\
Conventional SAGD 12 & 3.8 & 38.0 & 57 \\
Conventional SAGD 17 & 3.9 & 37.7 & 57 \\
Conv. SAGD 7, same Kr & 6.2 & 14.0 & 21 \\
Off-set SAGD 3 & 3.7 & 38.1 & 57 \\
Off-set SAGD 9 & 3.7 & 37.6 & 56 \\
Off-set SAGD 16 & 3.5 & 36.7 & 55 \\
Off-set SAGD 24 & 3.1 & 32.2 & 48 \\
Off-set 9 High Visc & 4.9 & 25.5 & 38 \\
Off-set 9 High Visc-Preheat & 3.6 & 31.0 & 47 \\
Off-set 9 High Visc-High $S_{\mathrm{w}}$ & 4.4 & 31.8 & 48 \\
Off-set 9 High Visc-High $K_{\mathrm{f}}$ & 4.2 & 38.7 & 58 \\
Staggered SAGD 2 & 4.3 & 38.2 & 57 \\
Staggered SAGD 8 & 4.1 & 39.3 & 59 \\
Staggered SAGD 13 & 4.1 & 38.6 & 58 \\
Staggered SAGD 18 & 3.9 & 39.0 & 59 \\
Vertical-Inj SAGD 5 & 3.5 & 34.2 & 51 \\
Vertical-Inj SAGD 10 & 3.5 & 34.7 & 52 \\
Vertical-Inj SAGD 15 & 3.6 & 33.4 & 50 \\
\hline
\end{tabular}

efficiency, while on the contrary its recovery factor is the lowest showing the same trend with that in sandstone. Regarding the economic analysis in the Vertical-Injection SAGD, one should take it into consideration that firstly, the capital expenditures (CAPEX) for drilling each vertical well is far lower than a horizontal one and secondly, the previous exploration wells can be utilized as the vertical injector, hence benefitting the process by lowering the CAPEX.

According to the investigated parameters and previous discussions on sensitivity analysis of fracture water saturation, fracture permeability and oil viscosity in all of the well patterns, we introduced a governing term for the oil production initiation. While the term is $\frac{S_{\mathrm{wf}} * K_{\mathrm{f}}}{\left(1+L_{\mathrm{hw}}\right) * \mu_{\mathrm{o}}}$ (where $S_{\mathrm{wf}}$ : fracture water saturation, $K_{\mathrm{f}}$ : fracture permeability, $L_{\mathrm{hw}}$ : horizontal well spacing and $\mu_{\mathrm{o}}$ : oil viscosity), higher values of this term result in faster well communication establishment and in turn, the oil production commencement. It is obviously observed that higher values of fracture water saturation and fracture permeability lead to sooner oil production threshold. Conversely, the increase in the amounts of horizontal well spacing and oil viscosity would delay the oil production initiation. The 1 in the parenthesis is to prevent the fraction to be infinitive since in the conventional SAGD $L_{\mathrm{wh}}$ is zero. 


\section{Conclusion}

The following remarks are concluded from this study:

- Staggered SAGD resulted in the highest oil recovery factor as well as CSOR compared to other well configurations. The Off-set pattern performance showed better results than conventional SAGD in the both terms of ultimate recovery factor and CSOR. Although the best thermal efficiency was seen in the vertical-injection SAGD pattern, undesirable cumulative oil production of this pattern deteriorated this promising result. Overall, selecting the most efficient and promising pattern was left to economic analysis.

- Generally, the second vertical well spacing cases in all patterns $(7-10 \mathrm{~m})$ are the most favorable intervals between the wells with the exception of Off-set configuration.

- In conventional SAGD process in NFR, preheating is not needed even in the cases of large well spacing and high oil viscosity, making it different from SAGD in sandstone.

- In the cases of off-set SAGD, horizontal well spacing delays the well connection establishment and early oil production, making preheating an essential part for this pattern.

- On the contrary to sandstone which connate water does not benefit the process due to its immobility, initial fracture water saturation is the key point in soon well connection establishment and fast steam chamber expansion rate in NFR. This conspicuous role of initial fracture water saturation was attributed to its high mobility due to zero irreducible water saturation in fracture.

- Finally, a governing term for the oil production initiation was introduced as $\frac{S_{\mathrm{w}} * K_{\mathrm{f}}}{\left(1+L_{\mathrm{hw}}\right) * \mu_{\mathrm{o}}}$ where higher values of this term result in faster well communication establishment and in turn, the oil production commencement.

Open Access This article is distributed under the terms of the Creative Commons Attribution License which permits any use, distribution, and reproduction in any medium, provided the original author(s) and the source are credited.

\section{References}

Alvarado V, Manrique E (2010) Enhances oil recovery: an update review. Energies 3:1529-1575. doi:10.3390/en3091529

Bagci AS (2004) The effect of fractures on the steam-assisted gravity drainage process. Energy Fuels 2004(18):1656-1664

Bagci AS, Samuel OM, Macky E (2007) Recovery performance of steam-alternating-solvent (SAS) process in fractured reservoirs' The paper 2007-040 was presented at the Petroleum Society's 8th Canadian international petroleum conference (58th annual technical meeting), Calgary, Alberta, Canada, 12-14 June 2007

Britton MW, Martin WL, Leibrecht RJ, Harmon RA (1982) The Street Ranch Pilot Test of fracture-assisted steamflood technology. Paper SPE 10707 presented at the 1982 SPE California regional meeting, San Francisco, CA, 24-26 March 1982

Butler RM (1991) Thermal recovery of oil and bitumen. Prentice Hall, New Jersey

Butler RM (2001) Some recent developments in SAGD. J Can Pet Technol 40(1):18-22 (distinguished authors series)

Chen MYS, Fong J (1997) Effects of well placement and critical operation conditions on the performance of dual well SAGD well pair in heavy oil reservoir. Paper SPE 39082 presented at the Fifth Latin American and Caribbean petroleum engineering conference and exhibition held in Rio de Janerio, Brazil, 30 Aug3 Sept 1997

Cimolai, Edmunds, Barrett, Solanki SC, Kantzas, Duan (2008) Bitumen mobilization in an oil-wet, fractured grosmont carbonate. Available at http://www.laricinaenergy.com/investor/tech/ GPS\%20Bitumen\%20Mobilization.pdf

Cimolai MP, Solanki SC, Esmunda NR (2010) Passive reservoir heating for improving bitumen recovery. J Can Pet Technol 49(11):30-42

Das D (2007) Application of thermal recovery processes in heavy oil carbonate reservoirs. Paper SPE 105392 presented at the 15th SPE Middle East oil and gas show and conference, Bahrian, 11-14 March 2007

Edmunds NR et al (1994) Review of phase a steam-assisted gravitydrainage test. SPERE May 1994 p 119

Edmunds N, Barrett K, Solanki S et al (2009) Prospects for commercial bitumen recovery from the grosmont carbonate, Alberta. J Can Pet Technol 48(9):26-32

Fatemi SM (2009) Simulation study of steam assisted gravity drainage (SAGD) in fractured systems. Oil Gas Sci Technol Rev IFP 64(4):477-487

Fattahi A, Akhondzade H, Nawi M, Hussin M, Namazi S (2012) Impact of reservoir heterogeneity on steam assisted gravity drainage in heavy oil fractured reservoirs. Energy Explor Exploit 30(4):553-566

Gao Y, Liu S, Zhang Y (2002) Implementing steam assisted gravity drainage through combination of vertical and horizontal wells in a super-heavy crude reservoir with top-water. Paper SPE 77798 was presented at the SPE Asia Pacific oil and gas conference and exhibition held in Melbourne, Australia, 8-10 Oct 2002

Laricina Company Operation Report (2010) Available at http://www. laricinaenergy.com/operations/saleski.html

Mollaei A, Maini B (2010) Steam flooding of naturally fractured reservoirs: basic concepts and recovery mechanism. J Can Petrol Technol 49(1):65-70

Murty C, Kunar RK, Bapco K et al (2009) Thermal EOR pilot plan for a shallow limestone reservoir (rubble zone) in Bahrain field, SPE 120569, Middle East oil and gas show and conference, Bahrain, p 15-18

Reis JC (1992) An analysis of oil expulsion mechanism from matrix blocks during steam injection in naturally fractured reservoirs. Situ 16(1):43-73

Rouke JC et al (1994) UTF project status and commercial potential. Petroleum Society of CIM and AOSTRA paper 94-40 presented at the 1994 annual technical meeting of the Petroleum Society of CIM, Calgary, 12-15 June 1994

Sahuquet BC, Spreux AM, Cwe B, Guittard MP (1990) Steam injection in a low-permeability reservoir through a horizontal well in Lacq Superieur field. Paper SPE 20526 presented at the $51 \mathrm{~h}$ annual technical conference and exhibition of the Society of Petroleum Engineer held in New Orieane, LA, 23-26 Sept 1990 
Sawhney GS, Liebe H, Butler RM (1995) Vertical injection wells for SAGD: a practical option or not? J Can Pet Technol 34(1):9. https://www.onepetro.org/journal-paper/PETSOC-95-01-06

Sedaee B, Rashidi F (2006) Application of the SAGD to an Iranian carbonate heavy oil reservoir. In: Proceedings of SPE Western Regional/AAPG Pacific Section/GSA Cordilleran Section Joint Meeting, 8-10 May, Anchorage, Alaska, USA

Shahin GT, Moosa R, Kharusi B, Chilek G (2006) The physics of steam injection in fractured carbonate reservoirs: engineering development options that minimize risk. Paper SPE 102186 was presented at the 2006 SPE annual technical conference and exhibition held in San Antonio, Texas, USA, 24-27 Sept 2006

Shin H, Polikar M (2005) Optimizing the SAGD process in three major Canadian oil-sands areas. Paper SPE presented at the 2005 SPE annual technical conference and exhibition held in Dallas, Texas, USA 9-12 Oct 2005
Solanki SC, Barrett K, Riva D et al (2010) The First SC-SAGD pilot in the Grosmont. Paper WHOCV 11-615, World heavy oil conference, March 2010

Tamer M, Gates ID (2009) Impact of well configuration on performance of steam-based gravity drainage process. Paper 2009-049 was presented at Canadian international petroleum conference (CIPC), Calgary, Alberta, Canada, 16-18 June 2009

Yuan J-Y, Jiang Q, Russel-Houston J et al (2010). Evolving recovery technologies directed towards commercial development of the grosmont carbonate reservoirs, CSUG/SPE 137941. Canadian unconventional resources and international petroleum conference, Calgary, Alberta, Canada, 19-21 Oct 2010 